\title{
The Effect of the Five-Cycle Learning (5 e's) Strategy on the Achievement of Creative Thinking Skills in Biology for the Tenth Grade in Al-Karak Governorate
}

\author{
Mr. OMAR FARIS ABDALLAH ALATHAMEEN
}

\begin{abstract}
The study aimed to investigate the impact of five-cycle learning (5 E's) strategy on achievement and developing creative thinking skills in biology among tenth graders in al- karak governorate. The study sample consisted of (65) students who were randomly selected from mutah secondary School for Boys in al- karak governorate. The study sample was divided into two groups: an experimental group (32 students), taught using the five-cycle learning strategy, and the control group consisting of (33) students, studied using the traditional method. To achieve the objectives of the study, the researchers prepared the teacher and student guide according to the steps of the five-cycle learning strategy on the unit of viruses and viroids and prions, and an achievement test was developed consisting of (20) of multiple choice items, and a test for creative thinking skills consisting of (10) items. The results of the study indicated that there were statistically significant differences $(\alpha \leq 05.0)$ between the mean scores of students in the post - achievement test and in the post - creative thinking test in favor of the experimental group. The study recommended training supervisors and teachers of scientific subjects on the fivecycle learning and in particular, biology's teachers.
\end{abstract}

Keywords: Five-cycle learning strategy (5 E's), achievement, creative thinking skills, tenth grade.

DOI: $10.7176 / \mathrm{JEP} / 12-26-07$

Publication date:September $30^{\text {th }} 2021$

\subsection{INTRODUCTION:}

Modern education has been interested in teaching thinking and refining its skills, so that the learner can implement the knowledge and information he obtains to achieve success he aspires to. The reason is that thinking is an indispensable need for peoples and societies; its value is no longer measured only by its natural resources, but also by minds used to formulate and develop knowledge, and the extent to which it accepts the amazing technological and informational changes that are taking place. This necessitate preparation of individuals who can adapt to scientific developments, and this will only come through developing teaching strategies to develop students' thinking skills.

Hence, thinking development has become one of the educational issues that receive care and attention in modern educational systems. As the goal of the educational process is no longer confined to providing students with knowledge and facts and filling their minds, but rather to develop their abilities to think properly. Education has been based on the principle of teaching students how to learn and how to think (Al-Sabbagh, 2013; Najm, 2012).

Creative thinking is seen as a skill that develops through training, mental growth and accumulation of experience. Therefore, it does not happen by chance and the learner has to be exposed to educational situations and activities that help develop creative thinking with all its levels (Al-Majali, 2016). Therefore, it is necessary to provide all educational opportunities that help develop creative thinking among students, and to follow all available means for this, whether by developing biology's curricula and educational materials or by following modern teaching and assessment methods

The development of creativity is one of the main goals. Creativity in teaching and learning biology's is the ability to generate information and biological ideas which are useful valuable at least for the student. The development of creativity begins with encouraging students to generate serious and original ideas, engaging in creative activities, providing the appropriate environment, creative teacher and climate. Learning biology's will help in developing creative thinking skills among students (Obeid, 2004: 285)

Among the strategies that are concerned with the development of learner's thinking and practical skills and are consistent with the way students learn the strategy of the five- cycle learning, and through this strategy students themselves undertake the process of investigation, exploration, and research, which refer to the constructivist theory (Al-Majali, 2016)

The strategy of the five-cycle learning initially consisted of three stages: exploration, reaching the concept, and application. Karplus project (1924) introduced some modifications; It appeared as a part of the development of science and biology's in the primary stage presented by the University of California (USA), and the learning cycle became composed of four stages: The discovery, the interpretation, the expansion, and the evaluation stage.

Biology Curriculum Study Team, which was headed by (Bybee) in 1993, elaborated a constructive teaching model called the five-stage learning cycle (5Es), and this model achieved success in teaching science and 
biology's. The reason perhaps for this success is due to the fact that the five-stage learning cycle is an investigative approach to thinking and work in learning and teaching, and this strategy is consistent with how students learn (Niederberger 2009)

\section{THE FIVE- CYCLE LEARNING STRATEGY CONSISTS OF THE FOLLOWING STAGES (AL- DABABNEH, 2015).}

1. THE (ENGAGEMENT) STAGE: At this stage, students become familiar with the educational task for the first time, and relate past and current learning experiences. The teacher reaches this stage by asking a question, an exciting event, defining a problem, or arranging a situation with the intent to attract students' attention to focus on the educational task, such as displaying a video clip, image, or a published piece of news.

2. EXPLORATION STAGE: The student participates in performing a task or activity using tools and materials in groups, and the role of the teacher is a facilitator. The teacher tells the learner what he will learn, and what he should know, and the teacher designs the activities of the exploration phase in order to provide students with a foundation that enables them to explore the structure of concepts and processes.

3. EXPLANATION STAGE: It is less student-centered, in which the teacher directs the students' thinking so that they build these concepts cooperatively. To achieve this, the teacher prepares the required classroom environment, and asks students to provide him with the information they have collected and helps them process and organize it mentally.

4. ELABORATION STAGE: the expansion is learner - centered and aims to help him mentally organize the experiences he obtained, by relating them to similar previous experiences; discovering new applications of what has been learned. Moreover, the concepts that have been built must be linked to other ideas and experiences in order to help the students think beyond their current thinking, and the teacher must ask the students to use the language of the concept to have another dimension. This is the right time to help students apply what they have learned by examples enrichment or additional experiences to spark other investigative skills.

5. EVALUATION STAGE: In this stage continuous evaluation is employed, and at certain points students should receive review about the appropriateness of their explanations. Evaluation is not limited to the end of the semester. Various evaluation tools should be used. Multiple procedures must be taken to conduct continuous evaluation of learning and encourage the construction of knowledge of the concept and scientific skills.

The strategy of the five- cycle learning goes beyond just paying attention to the content of the educational material to focusing on the scientific aspect and the way students learn, through discovery, experiences, and application to new ideas. Therefore, this strategy is concerned with developing thinking skills and the learner's practical skills, and it is consistent with how the students learn. It is through this course that students themselves investigate and that leads to learning in new situations based on the constructivist theory.

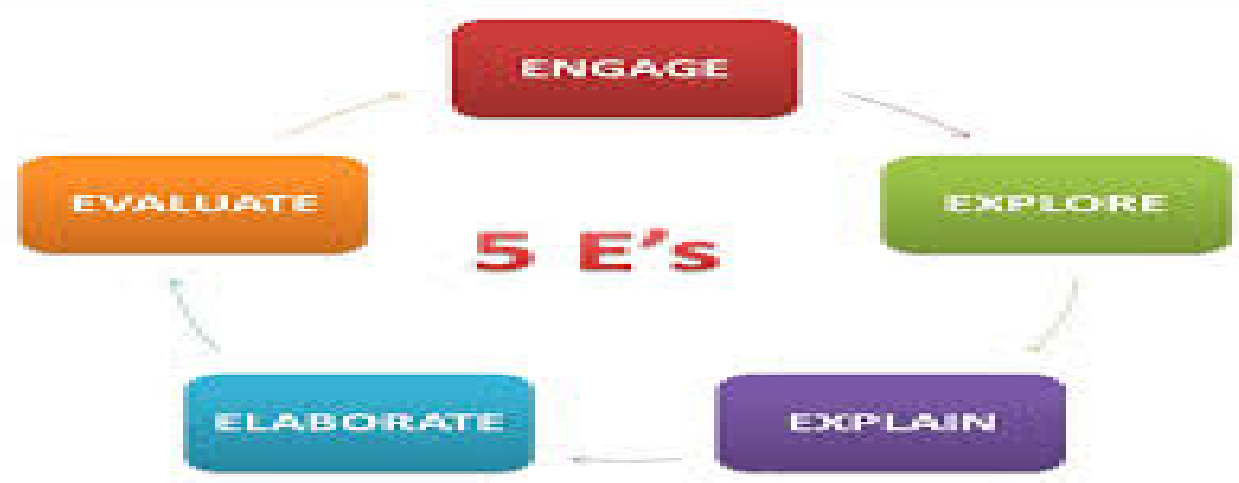

\subsection{STUDY PROBLEM, QUESTIONS AND HYPOTHESIS:}

science curricula have been of constant interest because they are of the basic foundations in developing student's experience, thoughts and skills. Organization and thought sequence are accomplished through these curricula and learners are capable of application what they learn in new and frequent situations.

In spite of changes that the content of biology curricula have undergone, the teaching strategies remain unchanged in that they still depend on the established and prevailing strategies based on narration style, dictation (Al Majali, 2016) .

This study attempts to answer the following main question:

What is the learning effect of the strategy of the five- cycle learning on the achievement and development of creative thinking skills in biology for the tenth graders in al-karak Governorate?

The following null hypotheses stem from this question:

First hypothesis: There are no statistically significant differences at the level $(\alpha \leq 0.05)$ between the mean 
scores of the two study groups in the post-achievement test attributed to the teaching method (the fivecycle learning strategy, and the traditional method).

The second hypothesis: There are no statistically significant differences at the level $(\alpha \leq 0.05)$ between the mean scores of the two study groups in the post creative thinking skills test due to the teaching method (the five-cycle learning strategy, and the traditional method).

\subsection{THE SIGNIFICANCE OF STUDY:}

This strategy is consistent with the call to activate the role of students through investigation, and it is distinguished from other strategies in that it takes into account learners' mental abilities, so it does not provide the learner with what he couldn't learn of concepts, and the learning proceeds from the part to the whole, and it leads the learner to think through the concept of imbalance which is the main motive towards searching for more scientific knowledge, and stimulating learners' thinking skills

\subsection{THE IMPORTANCE OF THE CURRENT RESEARCH CAN BE SUMMARIZED AS FOLLOWS:}

1. Providing models for lessons that include teaching the topics of viruses and viroids and prions unit for the tenth grade in accordance with the strategy of the five- cycle learning.

2. The current study presents a test to measure creative thinking skills in viruses and viroids and prions unit for the tenth grade, and this may help in construct other tests for multiple topics in biology.

3. It may help experts, specialists, supervisors, teachers and interested persons present a teaching strategy, which may contribute to develop creative thinking skills and achievement among the tenth grade students.

\subsection{STUDY DEFINITIONS:}

- Five-course learning strategy: a teaching strategy developed from the three-cycle learning and it is used by the teacher with his students in the classroom, and it aims for the learner to build his scientific knowledge by himself. (Bybee and Buchwald and Crissman, 1989).

-The researchers define it procedurally as a teaching strategy used to develop achievement and creative thinking in the viruses and viroids and prions unit for tenth grade students. This strategy consists of five successive stages: preparation, exploration, explanation and interpretation, expansion, and evaluation.

Creative thinking skills: they are the skills that students need to be able to produce a number of solutions to biological problems where the ideas of these solutions are diverse, atypical and unfamiliar (Al-Dabayba, 2015).

The researchers define them procedurally, as the skills that students need to make them able to produce a number of solutions to biologi problems in viruses and viroids and prions unit, and the diversity of the ideas of these solutions to go beyond typical solutions, and they measured the student through the test of creative thinking skills used in this study. This test included the following skills:

1. Fluency: It is the ability to render new ideas, alternatives, and solutions that are linked to a situation around a particular idea, in a specific period of time.

2. Flexibility: It is the ability to generate diverse and different ideas, and direct the course of thinking according to the requirements of the new situation.

3. Originality: the ability to produce ideas characterized by novelty, originality and creativity; That is, these ideas are unusual and non-stereotypical.

- Achievement: In this study, It is defined procedurally as the student's mark in the achievement test in viruses and viroids and prions unit prepared by the researchers for this purpose.

- tenth grade students: They are students aged (13-14 years) who are studying in the tenth grade for the academic year 2019/2020.

\subsection{STUDY LIMITATIONS:}

-The sample of this study was limited to (65) students from the tenth grade students from mutah Secondary School for Boys in al-karak Governorate .

-This study was conducted on viruses and viroids and prions unit in the first semester biology book for the tenth grade.

-The study was conducted in the first semester of the academic year 2019/2020.

\subsection{PREVIOUS STUDIES.}

(Al-Shehri, 2016) conducted a study aimed to know the effect of using the five-cycle learning strategy in teaching a unit of biology's for the fifth grade in developing achievement and retention of learning. The researcher followed the quasi-experimental approach. The study sample consisted of (59) students, who were divided into two groups: An experimental group, (30) students, and a control group (29) students from a school in Najran, Saudi Arabia, and the researcher prepared an achievement test consisting of (22) items .One of the research results was the superiority of the students of the experimental group who studied using the five-cycle 
strategy over the control group. in achievement in the post-test, as well as in learning retention.

(Al-Azmiya and Sherhid, 2015) conducted a study aimed at knowing the effect of using the five- cycle learning strategy in teaching a biology's unit for the seventh grade in developing achievement and biological thinking among students in Abyan Governorate - the Yemeni Republic. The researchers followed the experimental approach for the pre- and post-test. The study sample consisted of $(80$ students, who were divided equally into two groups: (experimental and control), and the researcher prepared two tests: An achievement test which consisted of (24) items, and the second for biological thinking, (24) items. The results of the research indicated the superiority of the experimental group students, who was taught using the five-cycle learning strategy, over the control group in achievement and in biological thinking skills. (Generalization, induction, symbolic expression, logical thinking, and biological proof). As well as in the biological thinking test as a whole, but there were no statistically significant differences between the two groups: the experimental and the control group in the skill of deduction.

\subsection{METHODOLOGY:}

The researchers adopted the quasi-experimental approach as it suits the nature of the current study, using two groups: the experimental group, which was taught by five-cycle learning, and the control group, which was taught through the traditional method, according to the following table (1).

Table (1): Experimental design of the study:

\begin{tabular}{|l|l|l|}
\hline \multicolumn{1}{|c|}{ Group } & \multicolumn{1}{c|}{ independent variable } & \multicolumn{1}{c|}{ dependent variable } \\
\hline Experimental group & Five- cycle learning strategy & - creative thinking \\
control group & traditional method & -Achievement \\
\hline
\end{tabular}

\subsection{STUDY POPULATION:}

The study population consisted of the tenth grade students in al-karak directorate of education during the first semester of the academic year 2019/2020, and number was (773) students in the Ministry of Education, 2020, distributed among (42) public schools.

As for the study members, they were (65) students from the tenth grade students from mutah Secondary School for Boys in al-karak Governorate. They were chosen purposively due to the cooperation of the administration and teachers with the researcher to conduct the study, and the students were distributed randomly into two groups:

- EXPERIMENTAL GROUP: studied viruses and viroids and prions unit using the strategy of the fivecycle learning, and it was (32) students.

- CONTROL GROUP: studied viruses and viroids and prions unit using the traditional method, and it was (33) students.

\subsection{THE EQUIVALENCE OF THE TWO STUDY GROUPS:}

To verify the equivalence of the experimental and control groups in pre- application achievement, the arithmetic means and standard deviations of members of the two study groups were calculated on the pre-achievement test, then the results of the t-test for independent samples were calculated to indicate the differences between the groups' averages, and Table (2) shows these results.

Table (2): Arithmetic means, standard deviations, and (t-test) results for the differences between the students' scores of the two groups: the (control and experimental) on the pre-achievement test.

\begin{tabular}{|l|c|c|c|c|c|}
\hline Group & Number & arithmetic mean & $\begin{array}{c}\text { standard } \\
\text { deviation }\end{array}$ & (t) value & $\begin{array}{r}\text { Statistical } \\
\text { significance }\end{array}$ \\
\hline Experimental & 32 & 7.36 & 1.92 & 0.17 & 0.932 \\
\hline Control & 33 & 7.22 & 2,57 & & \\
\hline
\end{tabular}

Statistical significance in the pre-achievement test indicated that there were no statistically significant differences $(\alpha \leq 0.05)$ between the mean scores of the pre-achievement test for the experimental and control groups, and this indicated the equivalence of the sample groups.

It was also ascertained that the groups in the study were equal in the creative thinking test prepared by the researchers before the application, as shown in Table No. (3). 
Table (3): Arithmetic averages and standard deviations of the scores of the students of the two groups:

( control and experimental ) on the pre- creative thinking test and the results of the (t) test.

\begin{tabular}{|c|c|c|c|c|c|c|}
\hline skill & Group & Number & $\begin{array}{l}\text { arithmetic } \\
\text { mean }\end{array}$ & $\begin{array}{r}\text { standard } \\
\text { deviation }\end{array}$ & $\begin{array}{l}\text { (t) } \\
\text { value }\end{array}$ & $\begin{array}{r}\text { Statistical } \\
\text { significance }\end{array}$ \\
\hline \multirow[t]{2}{*}{ fluency } & experimental & 32 & 0.83 & 2.42 & \multirow[t]{2}{*}{0.29} & \multirow[t]{2}{*}{0.75} \\
\hline & Control & 33 & 0.80 & 2.98 & & \\
\hline \multirow[t]{2}{*}{ flexibility } & experimental & 32 & 0.14 & 0.91 & \multirow[t]{2}{*}{0.10} & \multirow[t]{2}{*}{0.89} \\
\hline & control & 33 & 0.16 & 1.39 & & \\
\hline \multirow[t]{2}{*}{ originality } & experimental & 32 & 0.30 & 2.38 & \multirow[t]{2}{*}{0.29} & \multirow[t]{2}{*}{0.79} \\
\hline & control & 33 & 0.36 & 2.21 & & \\
\hline \multirow{2}{*}{$\begin{array}{l}\text { Total } \\
\text { score }\end{array}$} & Experimental & 32 & 1.45 & 1.85 & \multirow[t]{2}{*}{0.05} & \multirow[t]{2}{*}{0.87} \\
\hline & Control & 33 & 1.30 & 2.23 & & \\
\hline
\end{tabular}

Statistical significance in Table (3) indicated that there were no statistically significant differences $(\alpha \leq 0.05)$ between the mean scores of the two groups: the experimental group and the control group, according to their scores in the pre- creative thinking test, and this confirms the equivalence of the groups before the study conducting.

\subsection{STUDY TOOLS:}

- Preparation the teacher and student guide by the researchers of the unit to which the study is to be applied.

- Reliance on the theoretical basis of the five-cycle learning strategy.

- Researchers' development of an achievement test consisting of (20) multiple - choice items.

- Elaboration of a test to develop creative thinking skills consisting of (10) multiple - choice items

-Difficulty and discrimination coefficients for the achievement test items.

\begin{tabular}{|c|c|c|c|c|c|}
\hline Item number & $\begin{array}{c}\text { Difficulty } \\
\text { coefficient }\end{array}$ & $\begin{array}{c}\text { Discrimination } \\
\text { coefficient }\end{array}$ & Item number & $\begin{array}{c}\text { Difficulty } \\
\text { coefficient }\end{array}$ & $\begin{array}{c}\text { Discrimination } \\
\text { coefficient }\end{array}$ \\
\hline 1 & 0.55 & 0.45 & 11 & 0.44 & 0.56 \\
\hline 2 & 0.60 & 0.40 & 12 & 0.50 & 0.50 \\
\hline 3 & 0.72 & 0.28 & 13 & 0.70 & 0.30 \\
\hline 4 & 0.40 & 0.60 & 14 & 0.68 & 0.32 \\
\hline 5 & 0.39 & 0.61 & 15 & 0.68 & 0.32 \\
\hline 6 & 0.64 & 0.36 & 16 & 0.80 & 0.20 \\
\hline 7 & 0.66 & 0.34 & 17 & 0.55 & 0.45 \\
\hline 8 & 0.42 & 0.58 & 18 & 0.30 & 0.70 \\
\hline 9 & 0.56 & 0.44 & 19 & 0.47 & 0.53 \\
\hline 10 & 0.46 & 0.54 & 20 & 0.65 & 0.35 \\
\hline
\end{tabular}

$* *$ Statistically significant at the level of significance $(\alpha \leq 0.05)$.

As for the reliability of the achievement test, it was applied to a sample of students from outside the study sample who studied the chosen unit, and the sample consisted of (22) students from the tenth grade, and it was re-applied after two weeks on the members of the same sample and the Pearson correlation coefficient was calculated for the of the pilot sample in both times and it was (0.92). The internal consistency coefficient was calculated, and the Cronbach's alpha coefficient was (0.82).

\subsection{STUDY PROCEDURES:}

-Preparation of study tools, achievement test and creative thinking test.

- Arbitration of academic and creative study tools by a group of arbitrators.

- Applying the achievement and creativity test to the pilot sample.

- Ensuring that the study groups are equivalent before applying the achievement and creativity test.

- Applying the achievement test and the test for creative thinking on the students of the two groups, the experimental group and the control group, with the aim of applying the lessons according to the five-cycle learning strategy.

- Extracting and interpreting the results of the study.

\subsection{STUDY VARIABLES:}

1. THE INDEPENDENT VARIABLE: The teaching method and it has two levels (the cycle - learning, the traditional method).

2. THE DEPENDENT VARIABLE: it has two levels (achievement, creative thinking). 


\subsection{STUDY RESULTS AND DISCUSSION:}

The results related to the first hypothesis and its discussion:

The first hypothesis: There was no statistically significant difference at the level $(\alpha \leq 05.0)$ between the mean scores of the two study groups in the post-achievement test ascribed to the teaching method (the five- cycle learning, and the traditional method).

To verify this hypothesis, the arithmetic means and standard deviations of students' scores of in the two groups: experimental and control were calculated on the pre and post achievement test, as shown in Table (6).

Table (6): Arithmetic means and standard deviations of students' scores for the two groups: the control and experimental on the pre and post achievement test.

\begin{tabular}{|l|r|r|r|r|r|}
\hline \multirow{2}{*}{ group } & \multirow{2}{*}{ Number } & \multicolumn{2}{c|}{ Pre test } & \multicolumn{2}{c|}{ Post test } \\
\cline { 4 - 7 } & & \multirow{2}{*}{$\begin{array}{l}\text { Arithmetic } \\
\text { means }\end{array}$} & $\begin{array}{l}\text { Standard } \\
\text { deviation }\end{array}$ & $\begin{array}{l}\text { Arithmetic } \\
\text { means }\end{array}$ & $\begin{array}{r}\text { Standard } \\
\text { deviation }\end{array}$ \\
\hline experimental & 32 & 8.33 & 1.87 & 14.34 & 3.79 \\
\hline control & 33 & 8.23 & 2.64 & 11.87 & 4.89 \\
\hline
\end{tabular}

It is noted from Table No. (6) that there were apparent differences between the mean scores of the two groups: experimental, and control, and to identify whether these differences were statistically significant at the level of significance $(\alpha \leq 05.0)$, an analysis of covariance (ANCOVA) was performed, and it shows table (7) shows this analysis .

Table (7): The results of the analysis of covariance (ANCOVA) for the difference between the means of the students of the two study groups in the post-achievement test.

\begin{tabular}{|c|c|c|c|c|c|}
\hline $\begin{array}{c}\text { Source of } \\
\text { variance }\end{array}$ & Sum of squares & (d.f ) & $\begin{array}{c}\text { Mean of } \\
\text { square }\end{array}$ & (f) value & $\begin{array}{c}\text { Statistical } \\
\text { significance }\end{array}$ \\
\hline Pre- test & 674.68 & 1 & 674.68 & 70.26 & 0.19 \\
\hline Group & 100.80 & 1 & 100.80 & 8.62 & 0.00 \\
\hline Error & 266.90 & 62 & 6.43 & & \\
\hline Total & 1079.61 & 64 & & & \\
\hline
\end{tabular}

*Statistically significant $(\alpha \leq 05.0)$.

It is clear from Table (7) that there were statistically significant differences between the students' mean scores in the post-achievement test in favor of the experimental group. Statistical significance was $(0.00)$, and thus, the teaching provided to the experimental group in this study effectively contributed, through educational activities based on the strategy of the five- cycle learning, to improve students' achievement in viruse and viroids and prions unit. The researchers attributed this result to the fact that teaching according to the strategy of the five- cycle learning has led to interaction with the educational situation through direct activity carried out by students, which contributed to learn concepts functionally, relate them to what was previously learned, and form a sound knowledge structure.

This result can also be attributed to the integrated, multiple and comprehensive steps in the five-cycle learning strategy, being complementary and helpful for students to organize the information and concepts in their minds to be then remembered and recalled, and this led to enhance achievement as the engagement stage contributed to draw attention to the topic of the lesson, and identify alternative and incorrect information that students had. It is a prelude to the exploration stage which contribute to increase their motivation towards research, investigation and carrying out activities. As for the stage of explanation, it encouraged students to give appropriate answers, solutions, and explanations for the information in their own words, then the stage of application of this information to other similar situations using a set of skills such as: asking questions, proposing solutions, making decisions, and taking observations. The final stage is evaluation .s a continuous process throughout the lesson through direct observation, open- ended questions that require high mental abilities,

\subsection{THE RESULTS RELATED TO THE SECOND HYPOTHESIS AND ITS DISCUSSION:}

The second hypothesis: There was no statistically significant difference at the level $(\alpha \leq 05.0)$ between. the mean scores of the two study groups in the post creative thinking skills test attributed to the teaching method (the five-cycle learning strategy, and the traditional method).

To verify this hypothesis, the arithmetic means and standard deviations of the students' scores were calculated for the experimental and control groups on the post- creative thinking test. Table 8 shows these results. 
Table (8): the arithmetic averages and standard deviations of the scores of the students of the two experimental and control groups on the dimensional creative thinking test.

\begin{tabular}{|c|l|c|c|c|}
\hline \multirow{2}{*}{ Skill } & \multicolumn{1}{|c|}{ Group } & number & Arithmetic mean & $\begin{array}{c}\text { Standard } \\
\text { deviation }\end{array}$ \\
\hline \multirow{2}{*}{ Fluency } & experimental & 32 & 12.25 & 1.45 \\
\cline { 2 - 5 } & Control & 33 & 4.38 & 1.24 \\
\hline \multirow{2}{*}{ Flexibility } & experimental & 32 & 6.24 & 0.67 \\
\cline { 2 - 5 } & Control & 33 & 3.59 & 0.35 \\
\hline \multirow{2}{*}{ Originality } & experimental & 32 & 13.56 & 2.60 \\
\cline { 2 - 5 } & Control & 33 & 3.57 & 3.01 \\
\hline \multirow{2}{*}{ Total score } & experimental & 32 & 30.05 & 3.10 \\
\cline { 2 - 5 } & Control & 33 & 11.54 & 35 \\
\hline
\end{tabular}

It is evident from Table (8) that the students' mean scores in the post-test creative thinking for the experimental group were higher than the students' mean scores in the control group in all creative thinking skills, and to find out whether these differences were statistically significant at the significance level $(\alpha \leq 05.0)$, covariance analysis (MANCOVA) was performed, and Table (9) shows this analysis.

Table (9): Results of the covariance analysis (MANCOVA) for the difference between the mean of the students of the two study groups in the post-creative thinking test.

\begin{tabular}{|c|c|c|c|c|c|c|}
\hline $\begin{array}{l}\text { Source of } \\
\text { variation }\end{array}$ & Skill & $\begin{array}{l}\text { Sum of } \\
\text { squares }\end{array}$ & (d.f) & $\begin{array}{l}\text { Mean of } \\
\text { squares }\end{array}$ & F value & $\begin{array}{r}\text { Statistical } \\
\text { significance }\end{array}$ \\
\hline \multirow{4}{*}{ Method } & Fluency & 310.23 & 1 & 310.23 & 49,64 & $* 0,00$ \\
\hline & Flexibility & 123.43 & 1 & 123.43 & 10,35 & $* 0,00$ \\
\hline & originality & 175,33 & 1 & 175,33 & 38,76 & $* 0,00$ \\
\hline & Total & 608,99 & 1 & 608,99 & 76,45 & $* 0,00$ \\
\hline \multirow{4}{*}{ Error } & Fluency & 756,45 & 95 & 7,95 & & \\
\hline & Flexibility & 56,78 & 95 & 0,59 & & \\
\hline & originality & 389,76 & 95 & 4,10 & & \\
\hline & Total & 1202,99 & 95 & 12,66 & & \\
\hline \multirow{4}{*}{ Total } & Fluency & 1066,68 & 63 & & & \\
\hline & Flexibility & 180,21 & 63 & & & \\
\hline & originality & 565,09 & 63 & & & \\
\hline & Total & $1,811.98$ & 573 & & & \\
\hline
\end{tabular}

** Statistically significant $(\boldsymbol{\alpha} \leq \mathbf{0 . 0 5})$.

It is clear from Table (9) that there were statistically significant differences between the students' mean scores in the post- creative thinking test in favor of the experimental group in all creative thinking skills, and the statistical significance of the total score was (0.00), which is statistically significant at the level $(\alpha \leq 0,05)$. Thus, the strategy of the five- cycle learning has contributed to the development of creative thinking skills among the students of the experimental group.

The researchers explain that the five-cycle learning strategy encouraged students to have positive interaction and wide participation in group discussions. The students' interaction with each other in order to find multiple, diverse and new solutions to problems has provided the opportunity to trigger the energy of creativity, in addition to the style of work in the classroom based on the cooperation which would spread competitiveness among groups, and seek to put forward new ideas towards the solution, which led to greater understanding of ideas and activities. This strategy also links the variables to each other, and identify the subject to be studied The strategy of the five-year learning cycle is based on the teacher's and student's role where the student has the greater role. researchers have noticed that students' participation to a large extent in the educational process. this makes them more compatible with the biology teacher, and gives them opportunities to discuss ideas and learn proofs and how to build biological arguments and judge their validity. They can monitor their progress towards performing the educational task, which makes them more aware of their thinking, or In other words, they develop their reasoning because all of these processes provide an opportunity to develop creative thinking skills and propose multiple, diverse and new ways to solve .

\subsection{RECOMMENDATIONS:}

In light of the research results, the researchers recommend the following:

1. Encouraging biology teachers to implement the strategy of the five- cycle learning in teaching biology, given what this study revealed of its impact on the development of creative thinking and achievement.

2. Inviting those in charge of planning the content of biology curricula to organize their content according to Five-cycle learning strategy. 
3. Conducting similar studies to identify the effect of the five-cycle learning strategy on other variables such as deductive and critical thinking.

4. Conducting similar studies on other classes, and within other topics of biology.

\section{REFERENCES}

-Al-Dabaiba, Nader (2015). The effect of using the Bybee model for teaching biology to develop biology concepts and creative thinking in Jordan. Unpublished doctoral thesis, University of Islamic Sciences.

-Al-Shatnawy, Issam and Al-Obaidi, Hani (2006). The effect of teaching according to two constructive models of Ma'til on the achievement of tenth -grade students in biology, The Jordanian Journal of Educational Sciences, 2(4:) 819-802

- Sabbagh, Sumaila (2013). Aspects of biology Thinking for the First, Second and Third Grades in Jordan, Damascus University Journal, 22(8): 422-319

- Al-Azmia, Adel and Sharheed, Ali (2015). The effect of using the five-cycle learning strategy to teach a unit of biology's for the basic seventh grade in the development of achievement and biology thinking among students in the governorate of Abyan, Republic of Yemen, The Arab Journal for Excellence and Development, 6(01:5-82)

-Al-Otaibi, Nawal (2008). The effectiveness of using the "learning cycle" method in biology's achievement and the development of critical thinking skills among second-grade intermediate students in of Makkah, an unpublished master's thesis, Umm Al-Qura University

-Eid, We'am (2014). The effect of teaching a proposed unit based on the (7E's) strategy in developing and retaining biology communication skills in geometry for tenth grade students in Gaza, an unpublished master's thesis, Al-Azhar University, Gaza.

Majali, Youssef (2016). The effect of using the five-cycle learning cycle model on the achievement and development of creative thinking among seventh-grade students in Arabic language in Al Qasr District Karak Governorate, Dirasat Journal, University of Jordan, 34 (0:85-56)

Alshehri, Mohammed.( 2016). The Impact of Using (5E's) Instructional Model on Achievement of biology's and Retention of Learning among Fifth Grade Students, Journal of Research \& Method in Education, 6(2): 43- 48.

Bybee, R.; Buchwald, C.; Crissman, S. (1989). Science and technology education for the elementary years: frameworks for curriculum and instruction. Andover, MA: The National Center for Improving Science Education.

Devrim, K; Ceren, T; Jale, Ç. (2009). Effectiveness of 5E Learning Cycle Instruction on Students Achievement in Cell Concept and Scientific epistemological Beliefs, ERIC ,NO 871023.

Susan (2009) "Incorporating Young Adult Literature into the 5Es Learning Cycle", Middle School Journal,

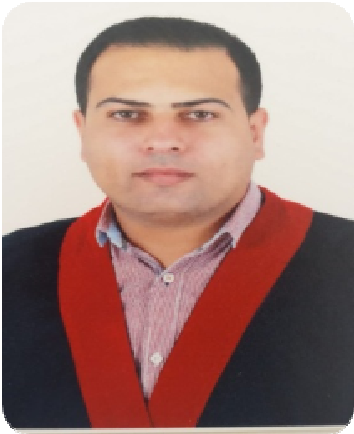

40(4): 25-33.

Mr. OMAR FARIS ABDALLAH ALATHAMEEN

omarbtoush55@gamil.com

JORDAN - ALKARAK 